\title{
Progressive collapse resistance of two typical high-rise RC frame shear wall structures
}

Peiqi Ren ${ }^{1}$, Yi Li ${ }^{2}$, Hong Guan ${ }^{3}$, Xinzheng $\mathrm{Lu}^{4}$

Abstract: Existing research on progressive collapse of building structures mainly focuses on concrete and steel frame structures. To investigate the progressive collapse resistance of high-rise

6 reinforced concrete (RC) frame shear wall structures, two typical 15-story building models are designed with equivalent overall lateral resistance to seismic actions. However the structural layouts in resisting the lateral forces are quite different for the two buildings. Building $\mathrm{A}$ is a weak wall-strong frame structure whilst Building $\mathrm{B}$ is a strong wall-weak frame system. 3-D finite

10 element models of the two structures are established using fiber beam and multilayer shell elements.

11 The progressive collapse resistances of the frames and the shear walls in both structures are evaluated under various column (shear wall) removal scenarios. Results demonstrate that there is a difference in progressive collapse prevention performance for different structural layouts. The progressive collapse resistance tends to be inadequate for the strong wall-weak frame system. Such a system is subsequently re-designed using the linear static AP method proposed in GSA2003, through which the reliability and efficiency of the method is confirmed. The outcome of this study has provided a reference for progressive collapse prevention designs of typical and representative 8 high-rise RC frame shear wall structures.

Key words: Progressive collapse; High-rise frame shear wall structure; Alternative load path method; Collapse resistance.

\section{Introduction}

Progressive collapse is considered as a type of chain reaction failure that follows the initial damage in a relatively small portion of a structure (Ellingwood and Leyendecker 1978). Progressive collapse of building structures, which is a significant threat to public safety, has been studied for

\footnotetext{
${ }^{1}$ Master Student, Key Laboratory of Civil Engineering Safety and Durability of Ministry of Education, Tsinghua University, Beijing 100084, China.

${ }^{2}$ Assistant Professor, Key Laboratory of Urban Security and Disaster Engineering of Ministry of Education, Beijing University of Technology, Beijing, 100124, China.

3 Associate Professor, Griffith School of Engineering, Griffith University Gold Coast Campus, Queensland 4222, Australia.

${ }^{4}$ Professor, Key Laboratory of Civil Engineering Safety and Durability of Ministry of Education, Tsinghua University, Beijing 100084, China.(corresponding author).Email: luxz@tsinghua.edu.cn.
} 
more than 40 years since the collapse of the Ronan Point Apartment in 1968.

Existing research studies have investigated the progressive collapse resistance of primarily frame type of structures via experimental and numerical methods. By the experimental means, Sasani et al. (2011a) studied the progressive collapse resistance of an actual 11-story RC frame structure following an initial damage of four adjacent columns and two beam segments. It should be noted that large-scale tests of an entire structural system remain challenging given the limitations of test facilities and costs involved. Thus, structural components or sub-structure systems are frequently tested to study their progressive collapse behaviors under large deformations. Such tests include: a one-third scale four-bay and three-story planner RC frame (Yi et al. 2008), continuous beam sub-assemblages ( $\mathrm{Su}$ et al. 2009), interior beam-column sub-assemblages (Kai and Li 2011), large-scale beam-column sub-assemblages (Sadek et al. 2011), a two-story steel moment frame (Chen et al. 2011) and a steel-concrete composite frame with rigid beam-to-column connections (Guo et al. 2013).

In addition to the experimental studies, numerical simulation techniques have also been extensively employed in collapse analysis because they are effective and suitable for studying the behavior of entire building structures. Parametric studies can also be easily conducted using numerical means, covering static or dynamic, linear or nonlinear analysis. Extensive numerical simulations of progressive collapse of frame structures have been performed, such as steel frames analyzed using the pushdown method (Kim et al. 2009), a 20-story steel frame structure considering different column removal scenarios (Fu 2009), an existing 8-story steel frame simulated using a nonlinear dynamic finite element procedure (Kwasniewski 2010), RC frame wall structures based on a macro model-based approach (Bao and Kunnath 2010), RC structures analyzed using a bar fracture model (Sasani et al. 2011b) and a steel frame building using a 3-D nonlinear model (Li and El-Tawil 2013). Despite these research efforts, existing numerical and theoretical studies primarily focus on the frames itself within a frame shear wall structure. The performance and contribution of the shear walls in the progressive collapse process are much less concerned. 
are designed according to the Chinese routine design codes, are established to evaluate their progressive collapse resistances via the nonlinear dynamic AP method. The structure that cannot effectively resist progressive collapse is re-designed using the linear static AP method specified in GSA guideline (GSA 2003), through which the reliability and efficiency of the existing design method are evaluated.

\section{Design Details of Two Frame Shear Wall Building Models}

The two frame shear wall building structures are referred to as Building A and Building B. They are designed following the Chinese design codes (i.e., the Code for Design of Concrete Structures (MOHURD 2010a) and the Code for Seismic Design of Buildings (MOHURD 2010b)). Buildings $\mathrm{A}$ and $\mathrm{B}$, both of 15 stories, have equivalent story heights - the height of the first story is $4.5 \mathrm{~m}$ and that of each remaining stories (the second to the fifteenth stories) is $3.6 \mathrm{~m}$. The total height of each building is $54.9 \mathrm{~m}$. The dead load on each story is $7.0 \mathrm{kN} / \mathrm{m}^{2}$, whereas the live load on each story is $2.0 \mathrm{kN} / \mathrm{m}^{2}$. Both buildings have the same seismic design intensity of VII (the peak ground acceleration for a $10 \%$ exceedance probability in 50 years is $0.10 \mathrm{~g}$, where $\mathrm{g}$ is the acceleration of gravity) and site class of II (soil shear wave velocity $500 \mathrm{~m} / \mathrm{s} \geq v_{\mathrm{s}} \geq 250 \mathrm{~m} / \mathrm{s}$ ). Such a seismic design requirement is equivalent to that the design ground acceleration is $0.10 \mathrm{~g}$ for type B ground and a non-collapse requirement specified in Eurocode 8 (CEN 2003). Due to the same seismic design intensity and site class chosen for both buildings, they are regulated to have the same seismic resistance and the same detailing requirement, i.e. the minimum reinforcement ratio and the maximum axial compression ratio of the structural components are identical. This in turn yields an identical overall lateral resistance for both buildings. The difference between the two buildings is that: Building A is a weak wall-strong frame structure whilst Building B is a strong wall-weak frame system, as is shown in their floor plan (symmetrical half) (see Figure 1). That results in Building A having higher reinforcement ratio in its frame beams and columns than that of Building B, which in turn leads to higher redundancy of the frames in Building A in resisting progressive collapse. For Building B, on the other hand, more $\mathrm{RC}$ walls are arranged to provide adequate lateral resistance for seismic prevention. As is shown in Figure 1, the shear walls are singly arranged in Building A but in Building B, they are arranged in a common "C" shape. 


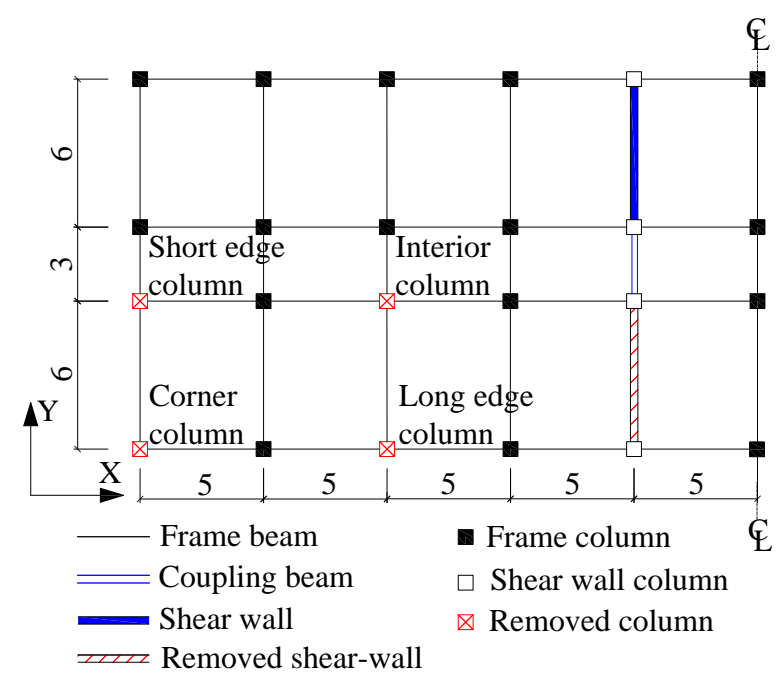

(a) Building A

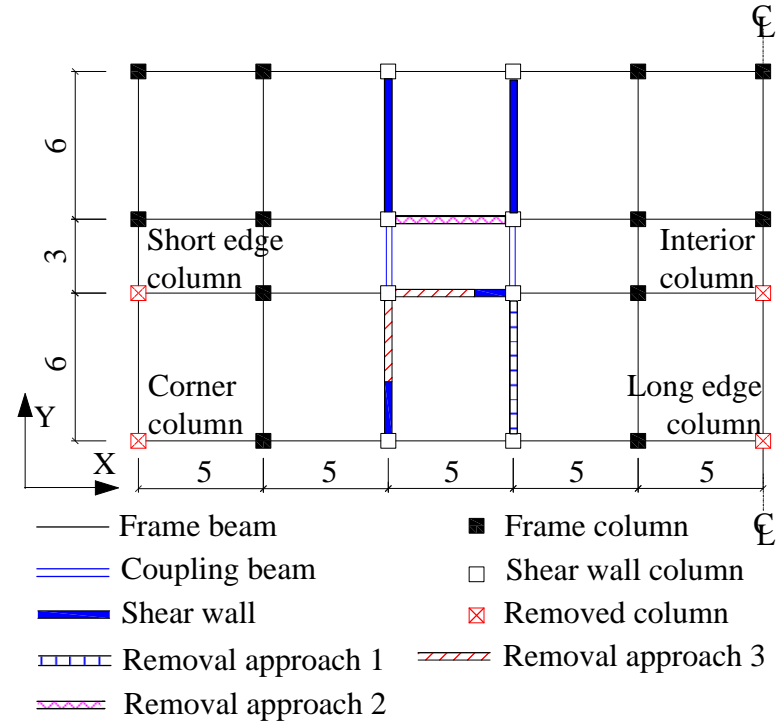

(b) Building B

Figure 1 Floor plan of the building models (unit: m)

Table 1 Parameters of structural elements in Building A and Building B

\begin{tabular}{|c|c|c|c|c|c|c|}
\hline & Building & Beams & Coupling beams & Columns & $\begin{array}{l}\text { Shear walls } \\
\text { (thickness) }\end{array}$ & $\begin{array}{l}\text { Floor slabs } \\
\text { (thickness) }\end{array}$ \\
\hline \multirow{2}{*}{ Cross Section } & A & $300 \mathrm{~mm} \times 600 \mathrm{~mm}$ & $400 \mathrm{~mm} \times 700 \mathrm{~mm}$ & $600 \mathrm{~mm} \times 600 \mathrm{~mm}$ & $400 \mathrm{~mm}$ & $120 \mathrm{~mm}$ \\
\hline & B & $250 \mathrm{~mm} \times 450 \mathrm{~mm}$ & $300 \mathrm{~mm} \times 700 \mathrm{~mm}$ & $600 \mathrm{~mm} \times 600 \mathrm{~mm}$ & $300 \mathrm{~mm}$ & $120 \mathrm{~mm}$ \\
\hline \multirow{2}{*}{ Concrete } & \multirow{2}{*}{$A \& B$} & \multirow{2}{*}{$\mathrm{C} 30\left(f_{\mathrm{c}}=20.1 \mathrm{MPa}\right)$} & \multirow{2}{*}{\multicolumn{4}{|c|}{$\begin{array}{l}1^{\text {st }} 10^{\text {th }} \text { story: } \mathrm{C} 40\left(f_{\mathrm{c}}=26.8 \mathrm{MPa}\right) \\
11^{\text {th }} \sim 15^{\text {th }} \text { story: } \mathrm{C} 35\left(f_{\mathrm{c}}=23.4 \mathrm{MPa}\right)\end{array}$}} \\
\hline & & & & & & \\
\hline \multirow{3}{*}{$\begin{array}{l}\text { Longitudinal } \\
\text { reinforcing steel }\end{array}$} & \multirow{2}{*}{ A } & HRB335 & \multirow{3}{*}{\multicolumn{4}{|c|}{$\mathrm{HRB} 400\left(f_{\mathrm{y}}=400 \mathrm{MPa}\right)$}} \\
\hline & & $\left(f_{\mathrm{y}}=335 \mathrm{MPa}\right)^{\mathrm{a}}$ & & & & \\
\hline & $\mathrm{B}$ & $\mathrm{HRB} 400\left(f_{\mathrm{y}}=400 \mathrm{MPa}\right)$ & & & & \\
\hline $\begin{array}{l}\text { Hoop reinforcing } \\
\text { steel }\end{array}$ & $A \& B$ & \multicolumn{5}{|c|}{ HPB $300\left(f_{\mathrm{y}}=300 \mathrm{MPa}\right)$} \\
\hline
\end{tabular}

Note: $f_{\mathrm{c}}=$ compressive strength of concrete; $f_{\mathrm{y}}=$ yield strength of steel

${ }^{a}$ As the beam section of Building $\mathrm{A}$ is relatively larger, lower strength steel is used to satisfy the minimum requirement of the reinforcement ratio specified in the design code. Otherwise, the beams will be significantly over-strength. 
91 The finite element models of Buildings A and B are established based on the general finite-element program MSC.MARC (MSC 2007), which has an excellent nonlinear computational capacity. The beams, columns and coupling beams are simulated using the fiber beam model developed by the authors, whereas the shear walls are simulated using the multilayer shell model of MSC.MARC. In addition to the brief description below of these two element models, more detailed information can be found in the work of Lu et al. (2013a). In the existing literature (Tsai and Lin 2008, Kokot et al. 2012), the slab contribution to the progressive collapse resistance was often neglected which produced conservative outcomes. This study follows the same strategies where the loads on the slab (including its own weight) are assigned to the corresponding beams according to the load 100 distribution relationship.

\section{Fiber Beam Model}

102 According to the successful work of Lu et al. (2013a), a section of the fiber beam model is divided 103 into 36 concrete fibers and 4 reinforcement fibers (see Figure 2a). Different material properties are 104 considered for steel, concrete cover (unconfined) and core (confined) concrete fibers. The concrete 105 constitutive model proposed by Légeron et al. (2005) is adopted to take into account the 106 confinement effect of the stirrups. The reinforcement fiber can be defined with equivalent 107 reinforcement area. Thus, cutoff of the longitudinal bars in beams can be modeled by altering the 108 reinforcement fiber areas at different sections along the beam. For the finite element models of 109 Buildings A and B, each frame element (beam or column) is subdivided into six fiber beam 110 elements to ensure sufficient accuracy (Lu et al. 2013a). 


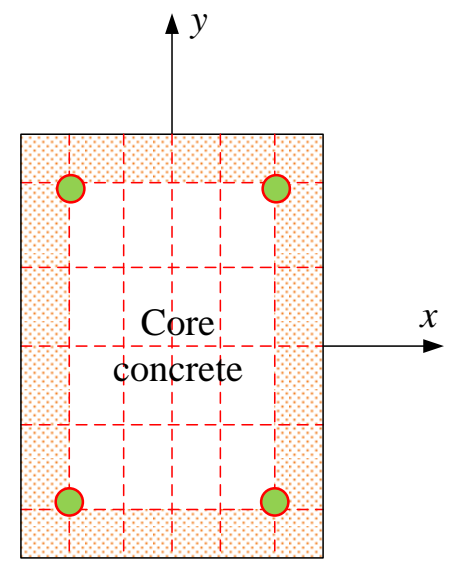

Concrete cover

Reinforcement fiber

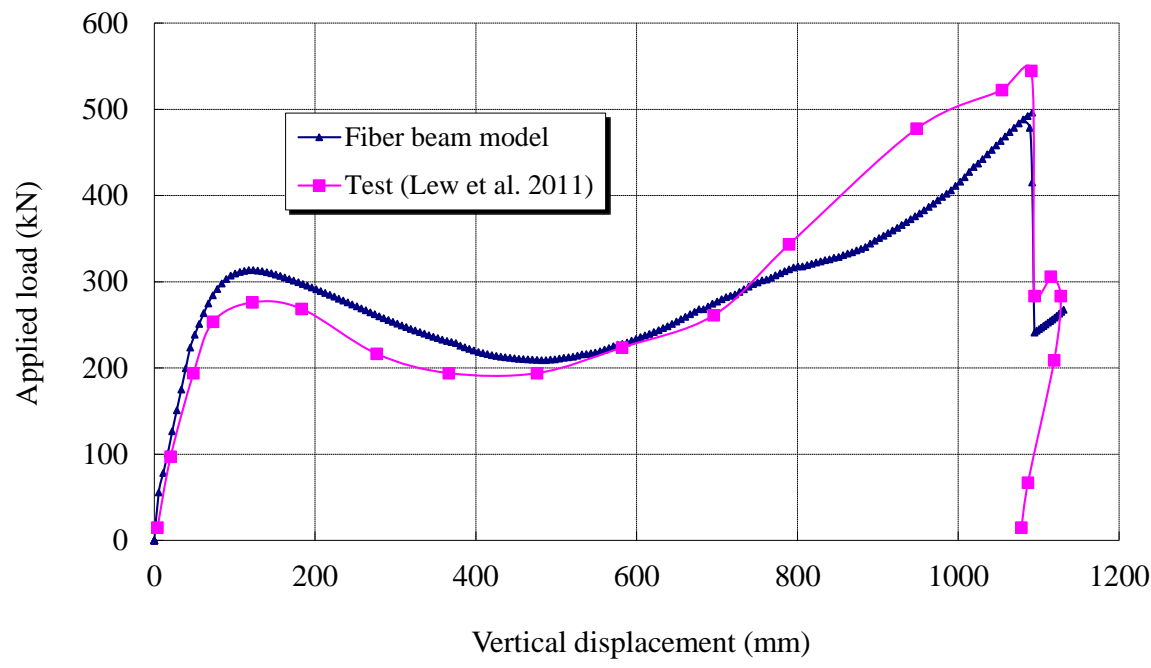

(b) Comparison between numerical simulation and test result Figure 2 Fiber beam model

In order to verify the feasibility and accuracy of the fiber beam model for simulating the

112 structural collapse, an experimental test of RC assemblies under a column removal scenario (Lew et

113 al. 2011) is simulated herein. Figure 2b indicates that the experimental load-displacement behavior 114 can be well predicted by the fiber beam model. Validation of the fiber beam model on both system 115 and component levels has also been done previously by Lu et al. (2013a) through simulation of two compressive-flexural column tests and a RC planner frame collapse test.

Multilayer Shell Model

118 In both buildings, the shear wall is made up of a middle wall and two boundary elements (see 119 Figure 3a). In the numerical model, the integrated shear wall is modeled by the multilayer shell 120 elements. The additional reinforcing bars within the boundary elements are simulated by the truss 121 elements which are embedded in the multilayer shell model at the corresponding nodal locations 122 (see Figure 3b). The mesh size of the multilayer shell element is $300 \mathrm{~mm} \times 300 \mathrm{~mm}$ and that of the 123 truss element is also $300 \mathrm{~mm}$ in the $\mathrm{Z}$ direction (see Figure $3 \mathrm{~b}$ ). The multilayer shell model is 124 composed of a number of concrete and steel layers, for which the thickness and material properties can be defined separately. The reinforcing bars in the shear walls are defined as one or more steel 126 layers with an equivalent reinforcement ratio. Based on the previous successful studies using the layered elements ( $\mathrm{Lu}$ et al. 2011, Lu et al. 2013a), each of the shear walls concerned is divided into 
128 ten concrete layers and four steel layers to simulate the longitudinal and transverse steel bars on 129 both the inner and outer sides of the wall. Note that MSC.MARC defines the steel layers following 130 a bilateral constitutive material law. As such, an orthotropic material model must be adopted for the 131 steel layers. In other words, the material properties are defined in the longitudinal direction of the 132 reinforcing bars while those in the orthogonal direction are defined as zero.

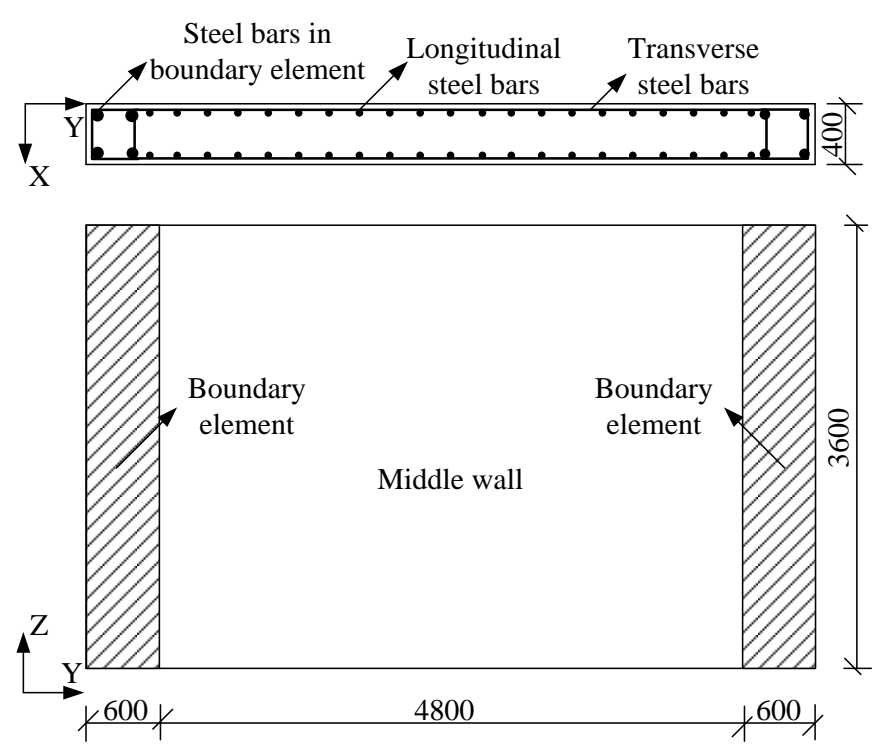

(a) Dimensions of the shear wall

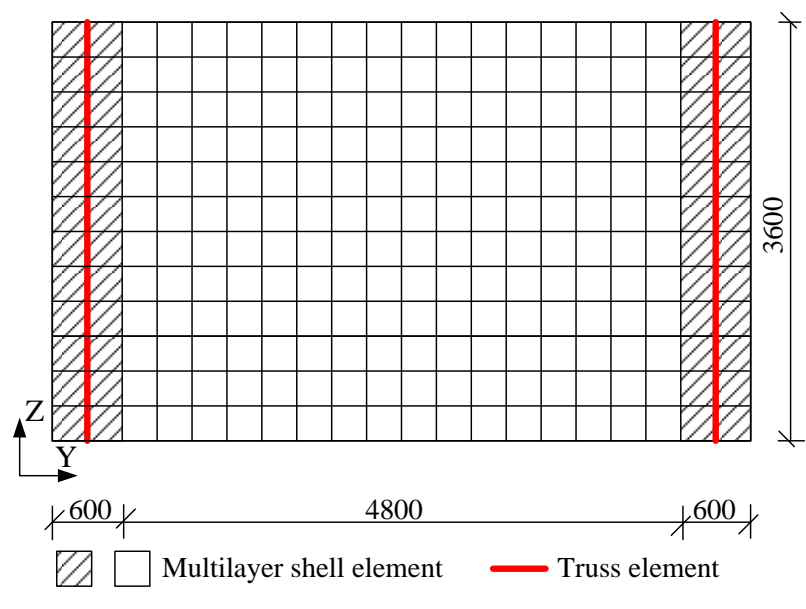

(b) Element mesh

Figure 3 Modeling of the shear wall

The multilayer shell element model (including the embedded truss element) has been validated

134 by Lu et al. (2013a) through simulation of a shear wall and two RC tube specimens. In addition, more successful applications of the above two types of elements in simulating structural collapses can be found in the work of Li et al. (2011) and Lu et al. (2011, 2013a, 2013b).

\section{Nonlinear Dynamic AP Analysis}

138 The nonlinear dynamic AP method is one of the most accurate methods for progressive collapse 139 analysis because it explicitly considers material and geometric nonlinearities, as well as the 140 dynamic effect. Using this method, progressive collapse resistances of these two RC frame shear 141 wall structures can be comprehensively studied, following sudden removal of frame columns or 142 shear walls. For column removals, four typical scenarios (i.e., a corner column, a long edge column, 
a short edge column and an interior column) on each story (see Figure 1) are assumed to be considered. Note that only one column is removed in each analysis.

For shear wall removals in Buildings $\mathrm{A}$ and $\mathrm{B}$, different removal approaches are considered according to DoD2010 (DoD 2010). The DoD2010 (DoD 2010) specifies that for each load-bearing wall of length greater than $2 H$, a length that is twice the clear story height $H$ can be removed; whereas if the length of the wall is less than $2 H$, the entire length of the wall can be removed. Based on these specifications, the entire length of the wall in the Y-direction (i.e., $6 \mathrm{~m}$ in Building A which is less than $2 H(2 H=7.2 \mathrm{~m}))$ is removed, as shown in Figure 1a. In Building B, three removal approaches of the inner load-bearing walls are implemented, as detailed in Figure 1b. "Removal approach 1" is similar to that used for Building A, i.e., the entire length of the shear wall in the Y-direction is removed. "Removal approach 2" refers to the removal of the entire length of the wall in the X-direction. For "Removal approach 3", a length of the wall that is equal to the story height $H$ in both the $\mathrm{X}$ - and Y-directions is removed from the inner walls, in which one or both of the interconnecting walls is load-bearing (DoD 2010). In this study, the removal scenarios of the shear walls from the bottom, mid and top stories (i.e., the $1^{\text {st }}, 7^{\text {th }}$ and $15^{\text {th }}$ stories) are considered to evaluate the progressive collapse responses of these two structures.

According to GSA2003 and DoD2010, the procedures of the nonlinear dynamic AP method involve: (a) starting at a zero load, monotonically increase the acceleration of gravity from 0 to $1 g$ to the entire model (i.e., the column or wall section has not been removed yet) until the gravity load is fully applied; and (b) after the static equilibrium in gravity load and internal forces is reached, the target structural element is rapidly removed and the nonlinear dynamic response of the structure is analyzed until the structure collapses or reaches a new steady state. In this paper, the DoD2010 collapse criterion for RC frames is used to identify the structural collapse. In the following analysis, it is found that when the vertical displacement of the joint (at the top of the removed column or shear wall) exceeds the threshold value specified in DoD2010, i.e. 1/5 of the shortest span of the connecting beams, the deformation of the structure continues to develop without converging, which confirms the rationality of the threshold value as the collapse criterion. 


\section{Progressive Collapse Resistance of the Two Structures}

\section{Removal of the Frame Columns in Building A}

172 As summarized in Table 2, no progressive collapse occurs in Building A irrespective of the removal 173 of any column from any story. As a typical example, Figure 4 presents the structural behavior 174 following the removal of the corner column from the $1^{\text {st }}$-story. To better illustrate the overall 175 deformation of this building, Figure 4a shows its deformed shape with a deformation amplification 176 factor of 20. The vertical displacement-time history responses of the joints at the top of the removed corner columns from selected stories are illustrated in Figure 4b, in which the removal of a column (or a shear wall in the last two sub-sections) on the $x^{\text {th }}$-story is represented by " $x^{\text {th }}$. Note that the displacement-time history response is presented from $0-1 \mathrm{~s}$ only in Figure $4 \mathrm{~b}$ because the displacements are found to reach a stable free vibration status prior to $1 \mathrm{~s}$. Figure $4 \mathrm{~b}$ also indicates that amongst the removal scenarios from three different stories, the removal of the $15^{\text {th }}$-story column results in the minimum displacement. When the column from the lower story is removed, larger axial force in the column is subsequently released, resulting in a larger vertical displacement at the joint (top of the removed column). It can be observed from Figure $4 \mathrm{~b}$ that the largest vertical displacement of the joint is only $37.8 \mathrm{~mm}$, much smaller as compared to the span of the beam $(5 \mathrm{~m})$. According to the work of $\mathrm{Li}$ et al. (2011), when the vertical displacement of the joint is small, progressive collapse is predominantly resisted by the bending moment of the beam ends, namely, by the flexural capacity of the beam. For Building A, similar phenomena are also observed when the edge or interior column is removed. This is due to the strong frames of this building, in which the reinforcement in the beam ends exhibits higher redundancy. This in turn leads to higher flexural capacities of the beam ends and much enhanced progressive collapse resistance of the frames within Building A. The above analysis results confirm that Building A can provide an effective alternative load path after any typical frame column is removed; thus, progressive collapse can be prevented in this building. 
Table 2 Outcome of frame column removal scenarios for Building A and Building B

\begin{tabular}{|c|c|c|c|c|}
\hline \multirow{2}{*}{ Building analyzed } & \multicolumn{4}{|c|}{ Removed column } \\
\cline { 2 - 5 } & Corner column & Short edge column & Long edge column & Interior column \\
\hline Building A & No collapse & No collapse & No collapse & No collapse \\
\hline Building B & Collapse & No collapse & Collapse & Collapse \\
\hline
\end{tabular}

197

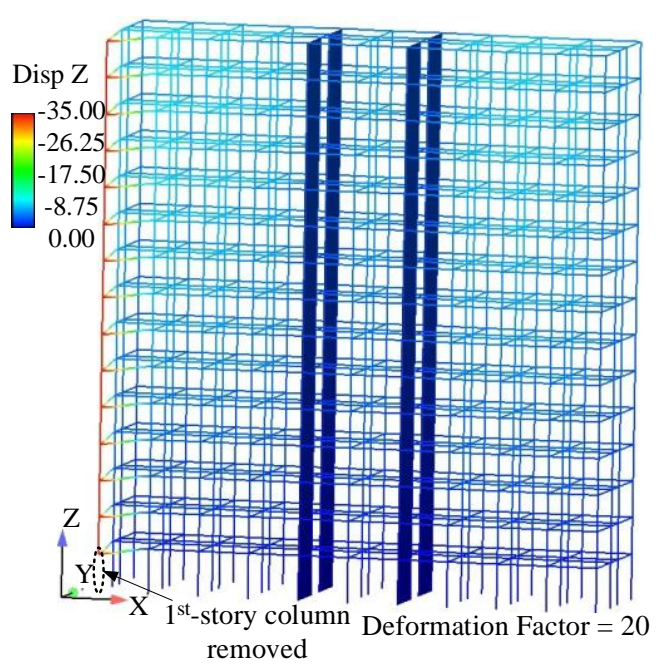

(a) After the corner column on the $1^{\text {st }}$-story is removed ( $\mathrm{t}=1.00 \mathrm{~s} /$ unit: $\mathrm{mm})$

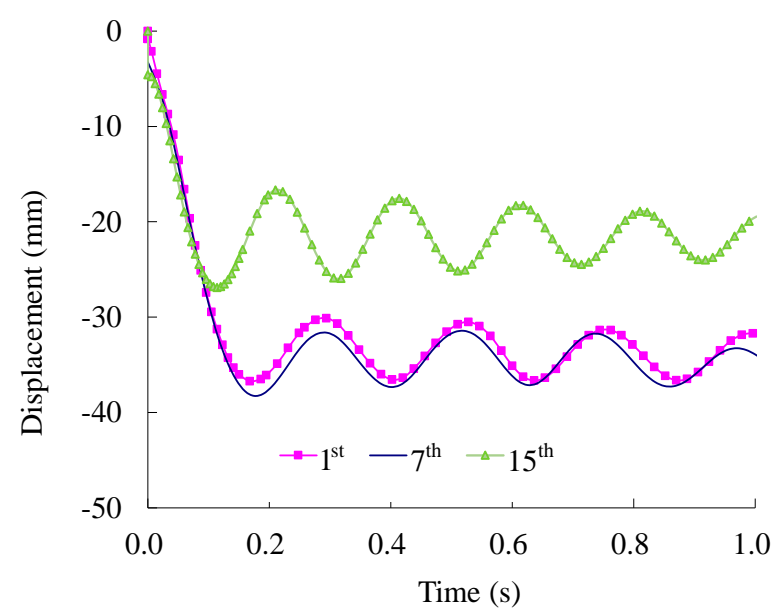

(b) Vertical displacement of the joint at the top of the removed column on the $x^{\text {th }}$-story

Figure 4 Removal of the corner column in Building A

\section{Removal of the Frame Columns in Building B}

199 For Building B, Table 2 indicates that progressive collapse does not occur when the short edge 200 column on any story is removed. However, collapse is triggered when the corner, the long edge or 201 the interior column is removed from any story. Following removal of the short edge column, the 202 amount of unbalanced gravity loads resisted by the connecting beams is less than that resisted by 203 the beams in the other areas. This implies that the progressive collapse resistance demand under the 204 short edge column removal scenario is the lowest, which enables the survival of the building after a column removal catastrophe. As a typical example, Figure 5 demonstrates the removal scenario of

206 the long edge column in Building B. The deformed shape due to the $7^{\text {th }}$-story column removal is presented in Figure 5a, in which progressive collapse is found to occur on and above the $7^{\text {th }}$-story.

208 Figure $5 \mathrm{~b}$ shows that the vertical displacement of the joint continues to increase to more than $1 \mathrm{~m}$ 
(i.e., 1/5 of the beam span) without converging, and an irreversible collapse process occurs. Figure

$2105 \mathrm{~b}$ also displays the displacement-time history responses after the long edge column is removed

211 from the $1^{\text {st }}$ and the $15^{\text {th }}$ stories. Similar progressive collapse phenomena are also observed.

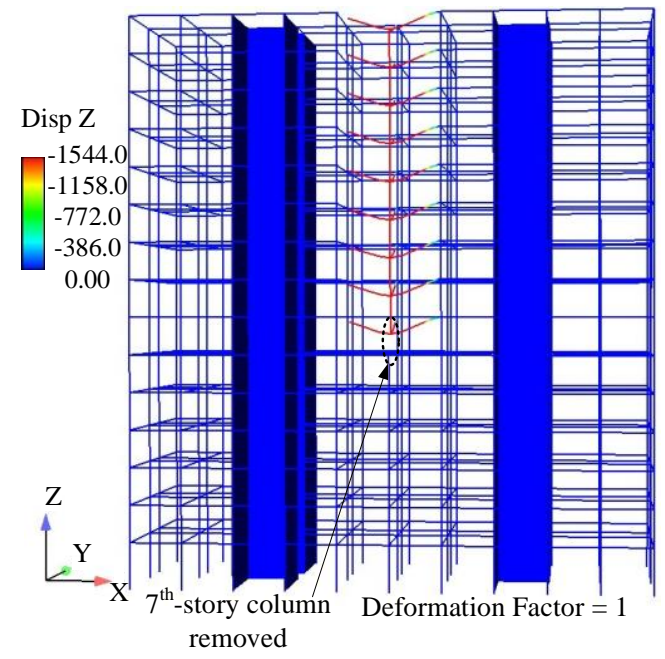

(a) After the long edge column on the $7^{\text {th }}$-story is removed $(t=0.83 \mathrm{~s} /$ unit: $\mathrm{mm})$

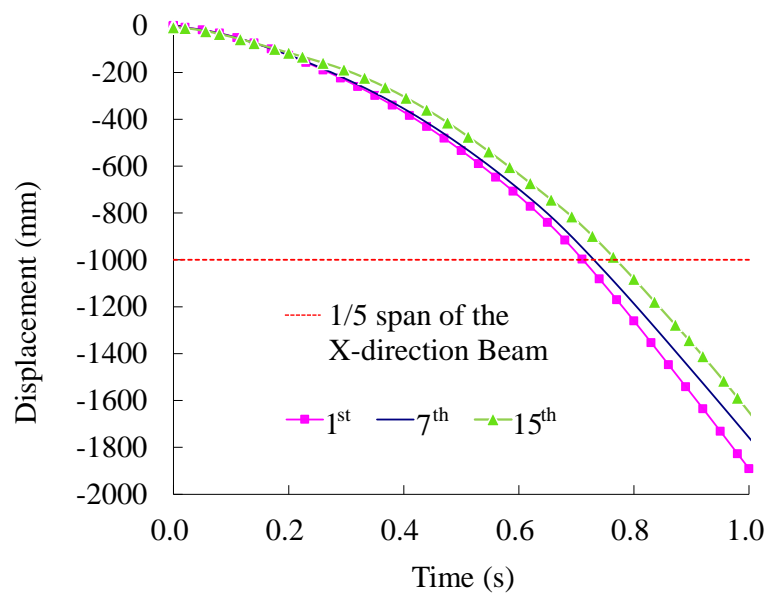

(b) Vertical displacement of the joint at the top of the removed column on the $x^{\text {th }}$-story

Figure 5 Removal of the long edge column in Building B

As mentioned previously, the frames in Building B are weaker than those in Building A, resulting in a significantly lower collapse resistance than that of Building A. The analysis results

214 reveal that the chosen high-rise RC frame shear wall structure (Building B), designed to provide lateral capacity mainly via the shear walls, presents a greater risk of progressive collapse on its frame component; thus, a special collapse prevention design is required.

\section{Removal of the Shear Wall in Building A}

218 For Building A, the analysis results indicate that progressive collapse does not occur when the shear 219 wall is removed from any representative story (i.e., $1^{\text {st }}, 7^{\text {th }}$, and $15^{\text {th }}$ stories). Figure 6 a illustrates the deformed shape of Building A after the shear wall in the Y-direction is removed from the $1^{\text {st }}$-story.

221 Figure $6 \mathrm{~b}$ shows the vertical displacement-time history responses of the joints (at the top of the removed wall) when the shear wall is removed from the $x^{\text {th }}$-story $(x=1,7$ and 15$)$. It is noted that when the shear wall on the lower story is removed, the joint displacement is larger and it takes longer for the structure to reach a stable state. Although a significant displacement is observed, the structure can reach a new stable state and progressive collapse does not occur. The maximum displacement of the joint is approximately $118 \mathrm{~mm}$, which is also significantly smaller than the 
227 threshold value for progressive collapse (i.e., 1/5 of the beam span, $1000 \mathrm{~mm}$ ).

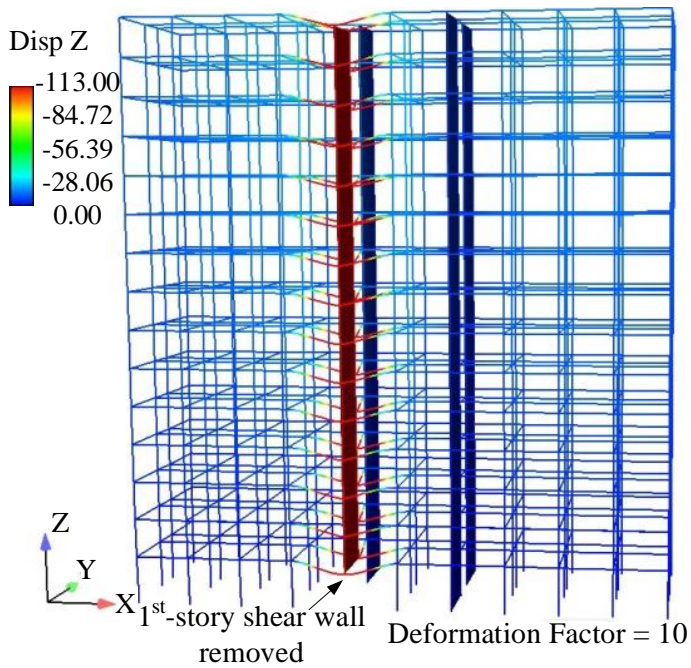

(a) After the $1^{\text {st }}$-story shear wall is removed $(t=1.50 \mathrm{~s} /$ unit

$\mathrm{mm}$

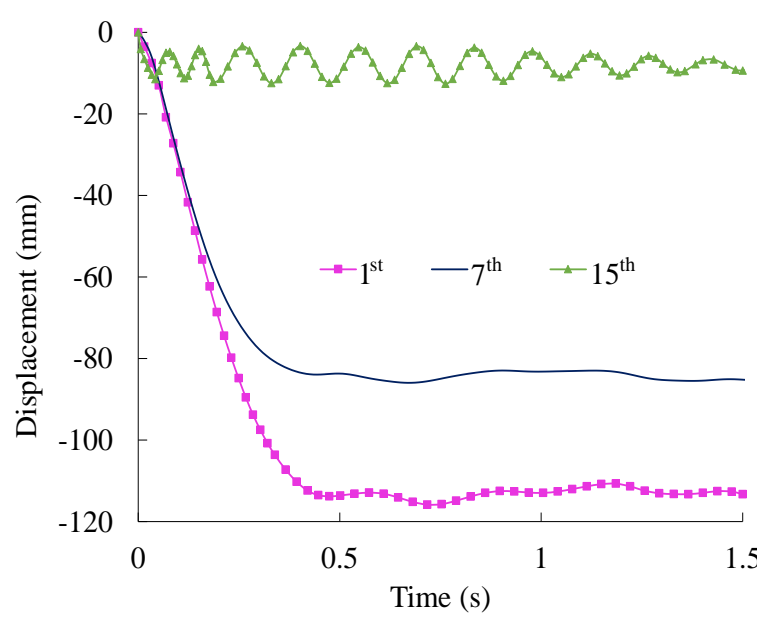

(b) Vertical displacement-time history of the joint after the removal of the $x^{\text {th }}$-story shear wall

Figure 6 Removal of the shear wall in Building A

\section{Removal of the Shear Wall in Building B}

229 For Building B, the shear wall removal is considered under three different removal approaches. The 230 analysis results reveal that regardless of which removal approach is selected, the structure can 231 adequately redistribute the unbalanced gravity loads to prevent progressive collapse after the shear 232 wall is removed from any representative story. Figure 7a shows the deformed shape after part of the

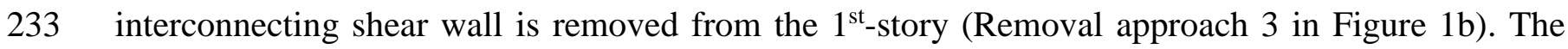
234 vertical displacement-time history responses of the joints (at the top of the removed wall), as 235 illustrated in Figure $7 \mathrm{~b}$, indicate that the structural deformation is very small (approximately 0.52 $\mathrm{mm})$. 


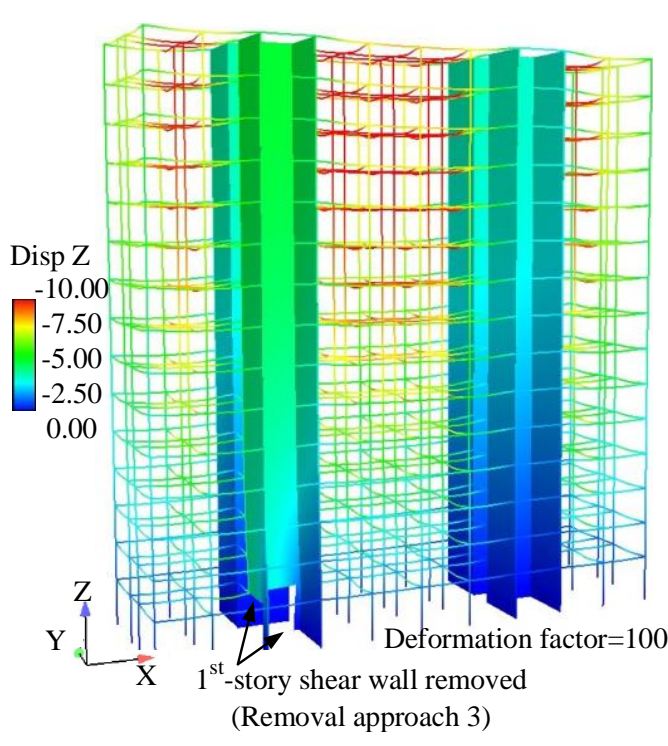

(a) After the $1^{\text {st }}$-story shear wall is removed (Removal approach 3) ( $t=1.00 \mathrm{~s} /$ unit: $\mathrm{mm})$

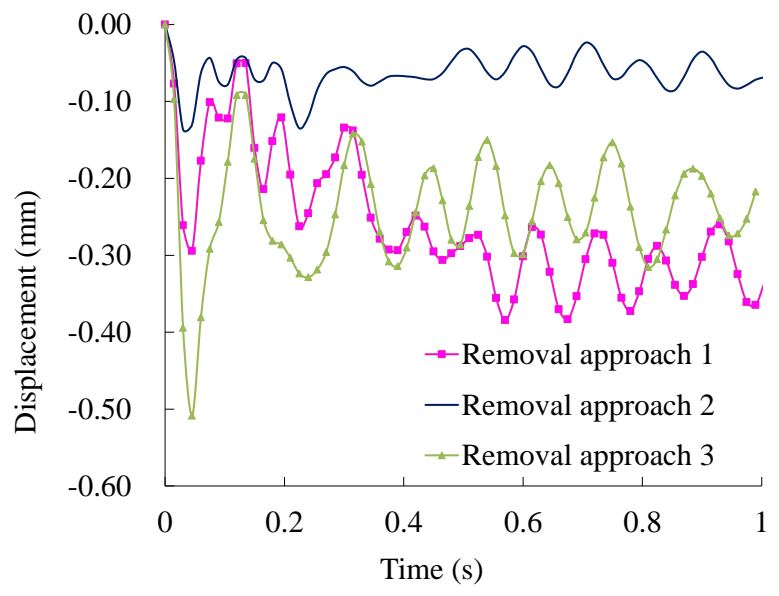

(b) Vertical displacement-time history after the removal of the $1^{\text {st }}$-story shear wall

Figure 7 Removal of the $1^{\text {st }}$-story shear wall in Building B

Although the design redundancy of the frame (mainly influenced by the reinforcement ratio and the member size) in Building B is much lower than that in Building A, the vertical displacement of Building B following the removal of the $x^{\text {th }}$-story shear wall is much smaller. This is because the redundancy of the shear walls (mainly influenced by the number and arrangement of the shear walls while the reinforcement ratio has less effect) in Building $\mathrm{B}$ is larger as its shear walls are interconnected to form a " $\mathrm{C}$ " shape (Figure $1 \mathrm{~b}$ ). Thus the deflection response of Building $\mathrm{B}$ is significantly reduced, resulting in better performance than Building A, in which the shear walls are arranged in only one direction. For Building A, in spite of the lower redundancy of the shear walls, the frame connected with the removed shear wall has higher reinforcement ratio (in order to meet seismic resistant requirements) which can serve as an alternative load path to resist progressive collapse. In summary, in RC frame shear wall structures designed to satisfy the seismic requirements, the shear walls are robust enough to resist progressive collapse.

Despite the fact that both Buildings A and B can resist progressive collapse after the removal of the shear wall, their alternative load paths are rather different. Figure 8 displays the reaction forces $F_{\mathrm{Z}}$ at the column supports after the removal of the $1^{\text {st }}$-story shear wall in the Y-direction for Building A (Figure 8a) and Building B (Removal approach 1, Figure 8b). In Building A, the 
shear wall. On the other hand, the internal force redistribution in Building B relies primarily on the remaining interconnecting shear walls. Hence, Building B provides higher progressive collapse resistance under wall removal scenarios than Building A, because its "C" shaped walls have much higher redundant capacity than that of the frames in Building A.

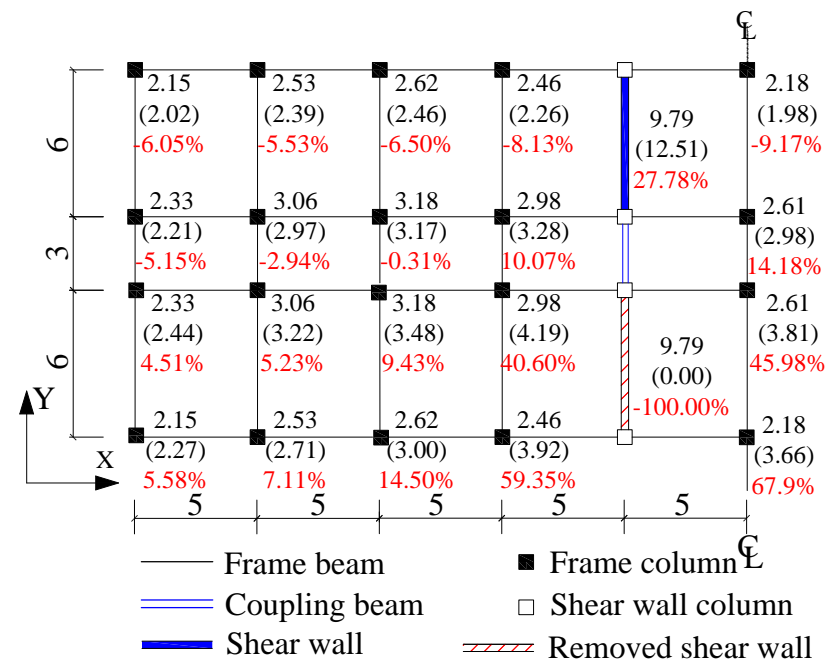

(a) Building A

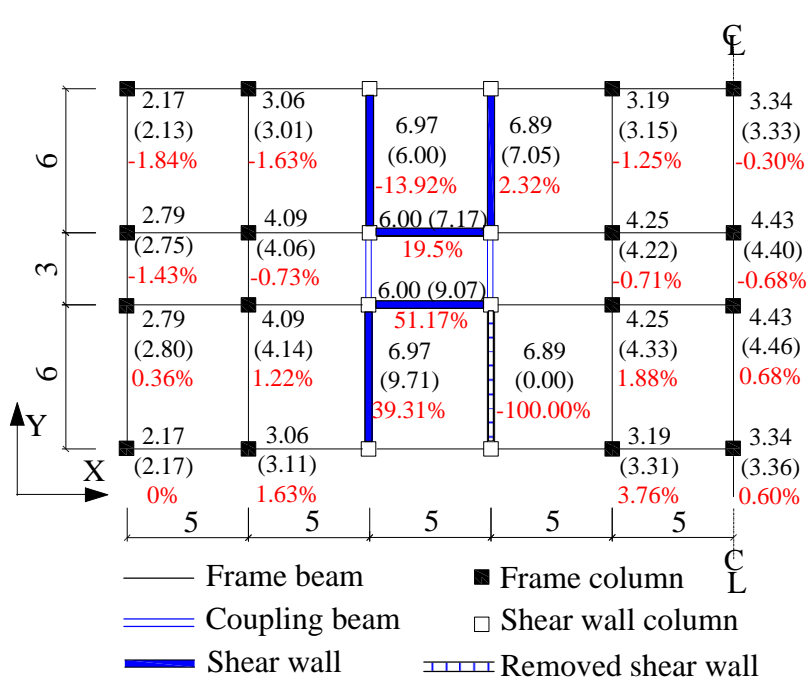

(b) Building B

Figure 8 Reaction force $F \mathrm{Z}$ at the column supports (unit:1000kN)

Note: $n_{1} ;\left(n_{2}\right) ; n_{3} \% . n_{1}: F_{\mathrm{Z}}$ before the removal of the shear wall; $n_{2}: F_{\mathrm{Z}}$ after the removal of the shear wall; $n_{3}:$ percentage difference in

\section{Progressive Collapse Prevention Design of the Frames in Building B}

The above nonlinear dynamic AP analysis results indicate that the collapse resistance of the frames in Building $\mathrm{B}$ is inadequate. As such, Building $\mathrm{B}$ is re-designed against progressive collapse through the linear static AP method specified in Section 4.1.2 and Section 4.1.3 of GSA2003. The step-by-step design procedure is as follows: (1) from the top floor to the bottom floor, remove a frame column from the location being considered (four respective locations on each floor, as is shown in Figure 1b) and conduct a linear-static analysis of the remaining structure. Only one column is removed in each analysis. The static loads applied to the model follow the values specified in GSA2003 (i.e. Load $=2(\mathrm{DL}+0.25 \mathrm{LL})$, where DL is the dead load and LL is the live load.). From the static analysis, the internal forces (e.g. the bending moments of the frame elements) $Q_{\text {UD }}$ can be obtained. (2) Conservatively set the $D C R$ values as 1.5 (for atypical structural configurations in GSA2003) for the frame elements. Then the expected ultimate $Q_{\mathrm{CE}}$ of the frame 
272 elements can be obtained by $Q_{\mathrm{UD}} / D C R$. (3) If the ultimate loading capacity of the frames is lower

273 than $Q_{\mathrm{CE}}$, then the frame element is re-designed (by increasing the amount of reinforcement)

274 according to $Q_{\mathrm{CE}}$ and the increased steel percentages are calculated. The analysis indicates that the 275 reinforcement ratio in frame columns is not necessary to be increased. For the mid-span sections of 276 beams, their ultimate bending capacities are usually larger than $Q_{\mathrm{CE}}$ and only a few sections need to 277 be re-designed by increasing the reinforcement ratio. However, the ultimate bending capacities at 278 the beam ends are much smaller than $Q_{\mathrm{CE}}$ and therefore the reinforcement ratio at these locations 279 must be considerably increased. This is in accordance with the research findings of Li et al. (2011) 280 in that progressive collapse resistance is predominantly provided by the bending moment of the 281 beam ends under small deformations. Table 3 summarizes the reinforcement amount in the frame 282 beams before and after performing the progressive collapse prevention design. It can be seen that 283 the reinforcement amount has an $8.70 \%$ increase in the re-designed structure.

Table 3 Comparison of the amount of longitudinal reinforcement in beams using different design methods for Building B

\begin{tabular}{|c|c|c|c|c|c|c|c|}
\hline \multirow[b]{2}{*}{ Story } & \multirow{2}{*}{$\begin{array}{c}\text { Original } \\
\text { Steel } \\
\text { reinforcement }(\mathrm{t})\end{array}$} & \multicolumn{3}{|c|}{ Linear static AP method } & \multicolumn{3}{|c|}{ Nonlinear dynamic AP method } \\
\hline & & $\begin{array}{c}\text { Steel } \\
\text { reinforcement (t) }\end{array}$ & Increase* $(\mathrm{t})$ & $\begin{array}{l}\text { Percentage } \\
\text { increase }\end{array}$ & $\begin{array}{c}\text { Steel } \\
\text { reinforcement }(t)\end{array}$ & Increase $*(t)$ & $\begin{array}{l}\text { Percentage } \\
\text { increase }\end{array}$ \\
\hline 15 & 2.415 & 2.632 & 0.217 & $9.00 \%$ & 2.478 & 0.063 & $2.61 \%$ \\
\hline 14 & 3.001 & 3.187 & 0.186 & $6.17 \%$ & 3.086 & 0.085 & $2.83 \%$ \\
\hline 13 & 3.001 & 3.169 & 0.168 & $5.57 \%$ & 3.086 & 0.085 & $2.83 \%$ \\
\hline 12 & 3.004 & 3.189 & 0.185 & $6.13 \%$ & 3.092 & 0.088 & $2.93 \%$ \\
\hline 11 & 3.004 & 3.200 & 0.196 & $6.52 \%$ & 3.092 & 0.088 & $2.93 \%$ \\
\hline 10 & 3.121 & 3.326 & 0.205 & $6.59 \%$ & 3.215 & 0.094 & $3.01 \%$ \\
\hline 9 & 3.121 & 3.333 & 0.212 & $6.82 \%$ & 3.215 & 0.094 & $3.01 \%$ \\
\hline 8 & 3.121 & 3.344 & 0.223 & $7.17 \%$ & 3.215 & 0.094 & $3.01 \%$ \\
\hline 7 & 3.121 & 3.357 & 0.236 & $7.59 \%$ & 3.215 & 0.094 & $3.01 \%$ \\
\hline 6 & 2.714 & 3.023 & 0.309 & $11.37 \%$ & 2.751 & 0.037 & $1.36 \%$ \\
\hline 5 & 3.031 & 3.298 & 0.267 & $8.79 \%$ & 3.107 & 0.076 & $2.51 \%$ \\
\hline 4 & 2.721 & 3.032 & 0.311 & $11.43 \%$ & 2.840 & 0.119 & $4.37 \%$ \\
\hline 3 & 2.721 & 3.049 & 0.328 & $12.05 \%$ & 2.840 & 0.119 & $4.37 \%$ \\
\hline 2 & 2.721 & 3.068 & 0.347 & $12.76 \%$ & 2.840 & 0.119 & $4.37 \%$ \\
\hline 1 & 2.598 & 2.983 & 0.385 & $14.81 \%$ & 2.718 & 0.120 & $4.62 \%$ \\
\hline Total & 43.415 & 47.190 & 3.775 & $8.70 \%$ & 44.790 & 1.375 & $3.17 \%$ \\
\hline
\end{tabular}

Note: $\mathrm{t}=$ tonne

${ }^{a}$ Compared with the original structure. 
For comparison, the nonlinear dynamic AP method is also used to re-design Building B through which the minimum demand of reinforcement to resist progressive collapse is obtained.

289 The design procedure follows that: (1) from the top floor to the bottom floor, conduct a dynamic 290 analysis for each column removal scenario as explained in the section "Nonlinear Dynamic AP 291 Analysis". Again, only one column is removed in each analysis. It should be noted that the loads 292 applied to the model are equal to DL+0.25LL. (2) If collapse occurs after a column is removed, then 293 slightly increase the reinforcement ratio in the frame beams connected to or exactly above the 294 removed column. Note that, in this step, to ensure minimum reinforcement demand is met, the reinforcement ratio should be gradually increased. (3) Re-run Step 1 until no collapse occurs.

296 During the nonlinear dynamic design process, the initial static analysis results should be referred to, in particular those beam sections having much lower bearing capacity than $Q_{\mathrm{CE}}$. In addition, 298 increasing the reinforcement ratio at the beam ends is more effective to prevent collapse than 299 increasing it at the mid-span sections. Table 3 also lists the minimum demand of reinforcement 300 (with a $3.17 \%$ increase) in resisting progressive collapse which is calculated via the nonlinear 301 dynamic AP method. It is evident that the linear static AP method is slightly conservative as compared to the minimum reinforcement demand required by the nonlinear dynamic AP method.

To verify the reliability of the linear static AP method, the re-designed Building B is analyzed again using the nonlinear dynamic AP method. Results show that the re-designed structure can adequately resist progressive collapse following removal of any frame column from any story. This suggests that the progressive collapse resistance of Building B can be significantly enhanced after a collapse prevention design is implemented. Results also demonstrate that the linear static AP method specified in GSA2003 is reliable and efficient for collapse prevention designs of typical and representative high-rise RC frame shear wall structures.

\section{Conclusion}

311 Two typical 15-story RC frame shear wall building models, with equivalent overall lateral 312 resistance to seismic actions, are established in this study to evaluate their progressive collapse 313 resistances. However the structural layouts in resisting the lateral forces are quite different for the 
314 two buildings: One is a weak wall-strong frame structure and the other is a strong wall-weak frame 315 system. 3-D finite element models are constructed based on general finite element program 316 MSC.MARC. The modeling techniques are described in some detail with validations. The 317 progressive collapse resistances of the two building models are evaluated via the nonlinear dynamic 318 AP method under various column (shear wall) removal scenarios. The analysis results demonstrate 319 that: if the RC frame shear wall building is designed to resist the horizontal seismic actions mainly through the shear walls, the collapse resistance of the frames tends to be inadequate and thus, a 321 special collapse prevention design is required. On the other hand, if the frames serve as the main lateral-resistant components, then the overall collapse resistance can be enhanced by the seismic design and in turn a progressive collapse can be adequately prevented. Further, this study suggests that the shear walls should be interconnected in the floor plane, for example in a "C" or a tube shape, provided that the functional requirements can be met. This is because interconnected shear walls can provide adequate alternative load path and thus possess superior collapse resistance. Moreover, detailed progressive collapse prevention design procedure is given for frames with inadequate collapse resistance. The design and analysis outcomes also confirm that the linear static AP method specified in GSA2003 is reliable and efficient for progressive collapse prevention designs of typical and representative high-rise $\mathrm{RC}$ frame shear wall structures.

\section{Acknowledgement}

332 The authors are grateful for the financial support received from the National Basic Research 333 Program of China (2012CB719703), the National Science Foundation of China (No. 51222804, 334 51208011), Tsinghua University Initiative Scientific Research Program (2011THZ03) and Research 335 Program of Beijing Municipal Commission of Education (KM201310005025).

\section{References}

337 Bao, Y., and Kunnath, S. K. (2010). "Simplified progressive collapse simulation of RC frame-wall structures." Eng. Struct., 32(10), 3153-3162. two-story steel moment frame.” J. Perform. Constr. Facil., 26(5), 567-575. 
Department of Defense (DoD). (2010). Unified facilities criteria (UFC): design of structures to resist progressive collapse, Washington (DC).

Ellingwood, B. R., and Leyendecker, E. V. (1978). “Approaches for design against progressive collapse.” J. Struct. Div., 104(3), 413-423.

European Committee for Standardization (CEN). (2003). Eurocode 8: Design of structures for earthquake resistance. Part 1: General rules, seismic actions and rules for buildings, Brussels.

Fu, F. (2009). "Progressive collapse analysis of high-rise building with 3-D finite element modeling method." $J$. Constr. Steel Res., 65(6), 1269-1278.

General Service Administration (GSA). (2003). Progressive collapse analysis and design guidelines for new federal office buildings and major modernization projects, GSA, Washington, DC.

Guo, L. H., Gao, S., Fu, F., and Wang, Y. Y. (2013). "Experimental study and numerical analysis of progressive collapse resistance of composite frames.” J. Constr. Steel Res., 89, 236-251.

Kai, Q., and Li, B. (2011). "Experimental and analytical assessment on RC interior beam-column subassemblages for progressive collapse.” J. Perform. Constr. Facil., 26(5), 576-589.

Kim, T., Kim, J., and Park, J. (2009). "Investigation of progressive collapse-resisting capability of steel moment frames using push-down analysis." J. Perform. Constr. Facil., 23(5), 327-335.

Kokot, S., Anthoine, A., Negro, P., and Solomos, G. (2012). "Static and dynamic analysis of a reinforced concrete flat slab frame building for progressive collapse.” Eng. Struct., 40, 205-217.

Kwasniewski, L. (2010). "Nonlinear dynamic simulations of progressive collapse for a multistory building." Eng. Struct., 32(5), 1223-1235.

Légeron, F., Paultre, P., and Mazars, J. (2005). "Damage mechanics modeling of nonlinear seismic behavior of concrete structures.” J. Struct. Eng., 131(6), 946-954.

Lew, H. S., Bao, Y., Sadek, F., Main, J. A., Pujol, S., and Sozen, M. A. (2011). "An experimental and computational study of reinforced concrete assemblies under a column removal scenario." NIST Technical Note 1704, National Institute of Standards and Technology (NIST), Gaithersburg, MD.

Li, H., and El-Tawil, S. (2013). "Three-dimensional effects and collapse resistance mechanisms in steel frame buildings.” J. Struct. Eng., 10.1061/ (ASCE) ST.1943-541X.0000839.

Li, Y., Lu, X. Z., Guan, H. and Ye, L. P. (2011). "An improved tie force method for progressive collapse resistance design of reinforced concrete frame structures.” Eng. Struct., 33(10), 2931-2942.

Lu, X., Lu, X. Z., Guan, H., and Ye, L. P. (2013a). "Collapse simulation of reinforced concrete high-rise building induced by extreme earthquakes.” Earthq. Eng. Struct. Dyn., 42(5), 705-723.

Lu, X. Z., Lu, X., Guan, H., Zhang, W. K., and Ye, L. P. (2013b). "Earthquake-induced collapse simulation of a super-tall mega-braced frame-core tube building." J. Constr. Steel Res., 82, 59-71.

Lu, X., Lu, X. Z., Zhang, W. K., and Ye, L. P. (2011). "Collapse simulation of a super high-rise building subjected to extremely strong earthquakes.” Science China Technological Sciences, 54(10), 2549-2560.

Ministry of Housing and Urban-Rural Development of the People's Republic of China (MOHURD). (2010a). Code for design of concrete structures. (GB50010-2010), Beijing. 
378 Ministry of Housing and Urban-Rural Development of the People's Republic of China (MOHURD). (2010b).

379 Code for seismic design of buildings. (GB50011-2010), Beijing.

380 MSC. MARC (2007). "Element library.” User's Manual, vol. B, MSC. Software Corporation.

381 Sadek, F., Main, J. A., Lew, H. S., and Bao, Y. (2011). "Testing and analysis of steel and concrete beam-column 382 assemblies under a column removal scenario.” J. Struct. Eng., 137(9), 881-892.

383 Sasani, M., Kazemi, A., Sagiroglu, S., and Forest, S. (2011a). "Progressive collapse resistance of an actual 384 11-story structure subjected to severe initial damage.” J. Struct. Eng., 137(9), 893-902.

385 Sasani, M., Werner, A., and Kazemi, A. (2011b). "Bar fracture modeling in progressive collapse analysis of 386 reinforced concrete structures.” Eng. Struct., 33(2), 401-409.

387 Su, Y., Tian, Y., and Song, X. (2009). "Progressive collapse resistance of axially-restrained frame beams." ACI 388 Struct. J., 106(5), 600-607.

389 Tsai, M. H., and Lin, B. H. (2008). "Investigation of progressive collapse resistance and inelastic response for an 390 earthquake-resistant RC building subjected to column failure." Eng. Struct., 30(12), 3619-3628.

391 Yi, W. J., He, Q. F., Xiao, Y., and Kunnath, S. K. (2008). "Experimental study on progressive collapse-resistant behavior of reinforced concrete frame structures.” ACI Struct. J., 105(4), 433-4 